ORIGINAL ARTICLE

\title{
Effects of sodium citrate ingestion before exercise on endurance performance in well trained college runners
}

\author{
V Oöpik, I Saaremets, L Medijainen, K Karelson, T Janson, S Timpmann
}

Br J Sports Med 2003;37:485-489

See end of article for authors' affiliations

....................

Correspondence to: Dr Oöpik, Institute of Exercise Biology,

University of Tartu, 18

Ülikooli Street, Tartu

50090, Estonia;

vahuro@ut.ee

Accepted

1 November 2002

\begin{abstract}
Objective: To test the hypothesis that sodium citrate administered two hours before exercise improves performance in a $5 \mathrm{~km}$ running time trial.

Methods: A total of 17 male well trained college runners (mean (SD) VO $O_{2} \mathrm{MAX} 61.3(4.9) \mathrm{ml} / \mathrm{kg} / \mathrm{min}$ ) performed a $5 \mathrm{~km}$ treadmill run with and without sodium citrate ingestion in a random, double blind, crossover design. In the citrate trial, subjects consumed 1 litre of solution containing $0.5 \mathrm{~g}$ of sodium citrate/ $\mathrm{kg}$ body mass two hours before the run. In the placebo trial, the same amount of flavoured mineral water was consumed.

Results: The time required to complete the run was faster in the citrate trial than the placebo trial ( 1153.2 (74.1) and $1183.8(91.4)$ seconds respectively; $p=0.01$ ). Lower packed cell volume and haemoglobin levels were found in venous blood samples taken before and after the run in the citrate compared with the placebo trial. Lactate concentration in the blood sample taken after the run was higher in the citrate than the placebo trial $(11.9(3.0) \vee 9.8(2.8) \mathrm{mmol} / \mathrm{l} ; \mathrm{p}<0.001)$, and glucose concentration was lower (8.3 (1.9) $\vee 8.8$ (1.7) $\mathrm{mmol} / \mathrm{l} ; \mathrm{p}=0.02$ ).

Conclusion: The ingestion of $0.5 \mathrm{~g}$ of sodium citrate/ $\mathrm{kg}$ body mass shortly before a $5 \mathrm{~km}$ running time trial improves performance in well trained college runners.
\end{abstract}

$\mathrm{T}$ he accumulation of hydrogen ions $\left(\mathrm{H}^{+}\right)$is thought to cause fatigue during short term, high intensity exercise. ${ }^{1}$

There are several mechanisms by which an increase in acidity is believed to contribute to the onset of fatigue, including inhibition of key enzymes in the glycolytic pathway, ${ }^{2}$ inhibition of calcium release from the sarcoplasmic reticulum and its binding to troponin $\mathrm{C}^{3}$ and reduction of contractility of the muscle fibres. ${ }^{4}$ Therefore the tolerance of high intensity exercise may be limited by the ability of the body to counteract decreases in intracellular (muscle) as well as extracellular (blood) $\mathrm{pH}$ through its intrinsic buffering systems. Consequently, by increasing the buffering capacity of the body through the administration of buffering agents, performance of high intensity exercise should be improved. Indeed, the ingestion of alkalising agents such as sodium bicarbonate or sodium citrate has been reported to have a positive effect on performance in short term, intense exercise, ${ }^{5-11}$ although not all studies have supported this finding. ${ }^{12-17}$

Ibanez et $a l^{14}$ have suggested that a minimum production of lactic acid and $\mathrm{H}^{+}$may be needed during exercise for any significant effect of pre-exercise ingestion of alkalisers to be observed on the contribution of anaerobic glycolysis to overall energy generation in intensively working muscle. They noted that, in studies in which no effect was found after alkalosis, peak blood lactate under the placebo condition was lower $(6 \mathrm{mmol} / \mathrm{l})$ than in the studies in which a significant metabolic effect was observed $(9-18 \mathrm{mmol} / \mathrm{l}){ }^{14}$

Although endurance exercise relies heavily on aerobic energy production, the contribution of anaerobic glycolysis to the overall energy supply is shown by a significant increase in blood lactate level. For example, in a well trained runner, blood lactate concentration may rise more than $20 \mathrm{mmol} / \mathrm{l}$ after a $5000 \mathrm{~m}$ run. ${ }^{18}$ Thus it is evident that the use of buffering agents has the potential to enhance performance during this type of exercise.

It is important to note, however, that the effect of alkalisers on performance may also be based on mechanisms other than buffering effect at the peripheral level. For example, it is well known that afferent stimulation from various intramuscular receptors (including chemoreceptors) stimulates the autonomic centres in the central nervous system during exercise. ${ }^{19}$ The results of the study of Bouissou et al ${ }^{20}$ suggest that alkalosis may influence the afferent stimulation from contracting muscle and thereby induce significant changes in hormonal response to exercise in trained athletes. Because the nervous and endocrine system work in concert to initiate and control movement and all the physiological processes it involves, ${ }^{21}$ alkalisers probably affect central control of movement, although to the best of our knowledge the precise mechanisms have not yet been described.

Only a few studies have investigated the use of buffering substances as ergogenic aids during endurance exercise. Ingestion of sodium bicarbonate or sodium citrate has been shown to have no effect on running time to exhaustion at various treadmill velocities. ${ }^{22-24}$ In contrast, in another study, ${ }^{25}$ the subjects were able to exercise for a longer duration on a cycle ergometer at $80 \%$ of their maximal oxygen uptake $\left(\mathrm{V}_{2} \mathrm{MAX}\right)$ as a result of intravenous sodium bicarbonate infusion compared with a control condition. Two other studies ${ }^{26} 27$ also showed an ergogenic effect of sodium citrate ingestion on endurance performance capacity in trained subjects in cycle ergometer tests. However, Schabort et $a^{28}$ did not find any effect of sodium citrate ingestion on performance in a $40 \mathrm{~km}$ cycling time trial in male athletes.

Thus the evidence for any ergogenic effect resulting from ingestion of alkalisers before endurance exercise is equivocal. The variation in findings may be partially explained by differences in the type of testing protocol, exercise intensity and duration used, and the mode of exercise (cycling or running). It is also possible that the equivocal findings are due in part to differences in the length of time between the administration of the buffering substance and the initiation of exercise, which range from 30 minutes $^{24}$ to three hours. ${ }^{23}$ Therefore the purpose of this study was to test the hypothesis that sodium citrate administered two hours before a $5 \mathrm{~km}$ 
running time trial would improve performance in well trained college runners.

\section{METHODS \\ Study design}

The two treatment conditions, sodium citrate (citric acid trisodium salt; CIT) and placebo (PLC), were administered in a counterbalanced, crossover, randomly assigned, double blind manner, with each trial separated by seven to eight days.

\section{Subjects}

A total of 17 male well trained college runners participated in the study, the protocol of which was approved by the ethics committee of the University of Tartu, Estonia. The subjects gave their written informed consent and were screened by questionnaire to exclude those with pre-existing medical conditions that would contraindicate their involvement in the study. Their mean (SD) age, body mass, height, and $\dot{\mathrm{V}}_{2} \mathrm{MAX}$ at the beginning of the study were 20.9 (1.9) years, $75.6(5.4) \mathrm{kg}, 182.9 \quad(5.5) \mathrm{cm}$, and $61.3 \quad(4.9) \mathrm{ml} / \mathrm{kg} / \mathrm{min}$ respectively. They had been involved in regular training for $9.2(3.6)$ years.

\section{Procedure}

All the subjects visited the laboratory three times. The first occasion was to complete a maximal aerobic power test to determine $\dot{\mathrm{V}}_{2} \mathrm{MAX}$, and the other two were to undertake a $5 \mathrm{~km}$ time trial on the treadmill. The subjects were instructed to abstain from vigorous exercise during the day preceding each test. They were also advised to follow their habitual eating pattern throughout the study period. For each test day and the day preceding the visit to the laboratory, the subjects kept detailed physical activity and food diaries. The information obtained from the diaries completed before the first visit to the laboratory was used to remind the athletes of the pattern of physical activity and eating to follow before each subsequent test day. These measures were undertaken to ensure a stable nutritional and training status throughout the study period of 11-12 days.

$\dot{\mathrm{V}}_{2} \mathrm{MAX}$ was measured during a progressive exercise test performed on a treadmill (Runrace HC 1400; Technogym, Gambettola, Italy). The test began with a five minute warm up. The speed was then increased from the initial rate of $8 \mathrm{~km} / \mathrm{h}$ after every $200 \mathrm{~m}$ by $0.5 \mathrm{~km} / \mathrm{h}$ until the athlete was unable to maintain the pace. The protocol of the graded exercise used in this study is based on principles originally developed by Conconi et al..$^{29}$ Expired gas was sampled and analysed continuously using an online system (True Max 2400; Parvo Medics, East Sandy, Utah, USA). The analyser was calibrated before each subject was tested. Most of the subjects (11) reached their $\dot{\mathrm{V}}_{2} \mathrm{MAX}$ one to three stages before the last $200 \mathrm{~m}$ of the test. In the remaining six, $\dot{\mathrm{V}}_{2} \mathrm{MAX}$ was observed at the maximal running speed achieved during the test procedure. However, in all cases the respiratory exchange ratio reached 1.1 at the estimated $\dot{\mathrm{V}}_{2} \mathrm{MAX}$. The distance covered by the subjects during the $\dot{\mathrm{O}}_{2} \mathrm{MAX}$ test was 4.1 (0.5) $\mathrm{km}$ (range 3.40-5.41). The velocity of the last $200 \mathrm{~m}$ ranged from 16.0 to $20.5 \mathrm{~km} / \mathrm{h}$, depending on the athletic level of the subject examined.

The subjects reported to the laboratory in a three hour post-absorptive state. In the CIT trial, they ingested 1 litre of solution containing sodium citrate $(0.5 \mathrm{~g} / \mathrm{kg}$ body mass $)$. The latter was dissolved in mineral water with a low mineral content $\left(\mathrm{K}^{+} 90-120 \mathrm{mg} / \mathrm{l} ; \mathrm{Na}^{+} 30-70 \mathrm{mg} / \mathrm{l} ; \mathrm{Ca}^{2+} 35-70 \mathrm{mg} / \mathrm{l}\right.$; $\mathrm{Mg}^{2+} 30-50 \mathrm{mg} / \mathrm{l} ; \mathrm{Cl}^{-} 120-200 \mathrm{mg} / \mathrm{l} ; \mathrm{HCO}_{3}{ }^{-} 290-400 \mathrm{mg} / \mathrm{l}$ ) and flavoured with very low energy flavouring. In the PLC trial, 1 litre of the same mineral water was used; its taste was disguised by adding flavourings. The energy content of both drinks was less than $4.18 \mathrm{~kJ} / \mathrm{l}$. The solution was consumed within 10 minutes, and the body mass of the subjects was immediately measured. After 120 minutes during which the subjects were allowed to use the toilet but not to consume any food or beverages, body mass was measured again. They then performed their customary pre-race warm up for about five minutes before undertaking the $5 \mathrm{~km}$ time trial on the treadmill. During the race, the subjects were continuously verbally encouraged to run as fast as they could, but they were allowed to choose their actual running speed. Heart rate was monitored during the race using a cardiotester Polar PE 3000 (Polar Electro, Oy, Finland). The rating of perceived exertion (15 point Borg scale) was recorded after the first $2.5 \mathrm{~km}$ and after each $0.5 \mathrm{~km}$ thereafter.

\section{Biochemical analyses}

Blood samples $(4.5 \mathrm{ml})$ were drawn from an arm vein (vena intermedia cubiti). To facilitate the sampling procedure, a tourniquet was used for a few seconds before insertion of the needle. One sample was drawn before the standard warm up for each test run, and the second sample was obtained five minutes after the end of the $5 \mathrm{~km}$ time trial.

The ethylenediaminetetra-acetic acid treated blood sample was then used for measurement of haemoglobin concentration (cyanmethaemoglobin method; Boehringer Mannheim GmbH, Mannheim, Germany; diagnostic kit No 124729) and packed cell volume (by spun haematocrit). The values obtained were used to calculate changes in plasma volume. ${ }^{30}$ The remaining blood samples were immediately cooled by placing the Vacutainer tubes in ice cold water. The tubes were then centrifuged, and the plasma was stored at $-25^{\circ} \mathrm{C}$ for later lactate and glucose analysis. Lactate and glucose concentrations were measured enzymatically in plasma samples using diagnostic kits purchased from Biocon (VöhlMarienhagen, Germany): No 301 (lactate) and No 458 (glucose). The intra-assay coefficient of variation for haemoglobin, packed cell volume, lactate, and glucose in our laboratory is $1.6 \%(\mathrm{n}=27), 0.68 \%(\mathrm{n}=22), 1.0 \%(\mathrm{n}=10)$, and $1.2 \%(\mathrm{n}=10)$ respectively.

\section{Statistical analysis}

Conventional statistical analysis was used to calculate the mean and SD for each variable investigated. The distribution pattern of the data was tested using a one sample Kolmogorov-Smirnov test, and the differences between the means of variables were evaluated using paired samples Student's $t$ test. Statistical significance was accepted at $\mathrm{p} \leqslant 0.05$, and $\mathrm{p} \leqslant$ values 0.1 are reported to indicate trends.

\section{RESULTS}

The body mass of the subjects measured immediately after the CIT or PLC drink did not differ in the two trials (table 1). During the two hour period between consumption of the drink and initiation of exercise, body mass of the subjects was reduced to a much greater extent in the PLC trial than in the CIT trial. As a result, the subjects in the CIT trial started the $5 \mathrm{~km}$ treadmill run on average $0.7 \mathrm{~kg}(\mathrm{p}=0.03)$ heavier than in the PLC trial.

\begin{tabular}{|c|c|c|c|}
\hline \multirow[b]{2}{*}{ Treatment } & \multicolumn{3}{|c|}{ Body mass (kg) } \\
\hline & After drink & Before exercise & Change \\
\hline Placebo & 78.7 (5.9) & $77.5(6.1)$ & $-1.2(0.5)$ \\
\hline Citrate & 78.9 (5.5) & $78.2(5.6)^{*}$ & $-0.8(0.3)^{*}$ \\
\hline
\end{tabular}


It took the subjects significantly $(p=0.01)$ less time to complete the $5 \mathrm{~km}$ run after drinking sodium citrate than after consuming placebo (1153.2 (74.1) v 1183.8 (91.4) seconds respectively). It is noteworthy that 13 of the 17 subjects achieved faster runs after sodium citrate ingestion, and only four were faster in the PLC trial. The average speed of running in the CIT trial exceeded that measured in the PLC trial during the 2 nd and 4 th kilometre of the distance (fig 1 ): $15.8(1.2) \vee 15.4(1.4) \mathrm{km} / \mathrm{h}(\mathrm{p}=0.01)$ and $16.2(1.1) \vee 15.7$ (1.2) $\mathrm{km} / \mathrm{h}(\mathrm{p}=0.002)$. A trend towards a better performance in the CIT trial than the PLC trial was evident during the 3rd kilometre: $16.0(1.2) v 15.7(1.2) \mathrm{km} / \mathrm{h}(\mathrm{p}=0.06)$. In both trials the fastest average speed was achieved during the 5 th kilometre, but there was no difference between the trials: 16.9 (1.3) km/h for the CIT trial and 16.7 (1.2) km/h for the PLC trial, $\mathrm{p}=0.43$. The maximum speed achieved in the two trials did not differ: 17.7 (1.4) km/h for the CIT trial and 17.7 (1.3) $\mathrm{km} / \mathrm{h}$ for the PLC trial.

Heart rate during the run did not differ in the two trials, except that measured after three minutes (173.2 (12.0) beats/ min in the CIT trial $v 169.5$ (13.5) beats/min in the PLC trial; $\mathrm{p}=0.03)$. The maximum heart rate measured during exercise did not differ in the two trials: 194.8 (10.3) beats/min for the CIT trial and 193.7 (9.2) beats/min for the PLC trial.

The subjects' perception of effort was the same in the two trials throughout the exercise period. Rating of perceived exertion during the run ranged from 14.9 (1.9) to $18.7(0.8)$ for the CIT trial and from 15.4 (1.6) to 18.7 (1.3) for the PLC trial.

Packed cell volume and haemoglobin concentration increased significantly as a result of the run in both trials (table 2). In the CIT trial, significantly lower packed cell volume and haemoglobin levels were observed before and after exercise compared with the PLC treatment. The calculated relative decrease in plasma volume during exercise was similar in the two trials (table 2).

There were no differences in plasma lactate and glucose concentrations before the run between the trials (table 3). A significant increase in the level of both metabolites was observed as a result of the $5 \mathrm{~km}$ run. However, the plasma concentration of lactate was significantly higher and that of glucose significantly lower after the run in the CIT trial than in the PLC trial (table 3). These significant between trial differences were evident also after correction of the measured concentrations of lactate and glucose for the individual changes in plasma volume (data not shown).

\section{DISCUSSION}

The primary finding of this investigation is that sodium citrate ingestion improved performance in a $5 \mathrm{~km}$ treadmill

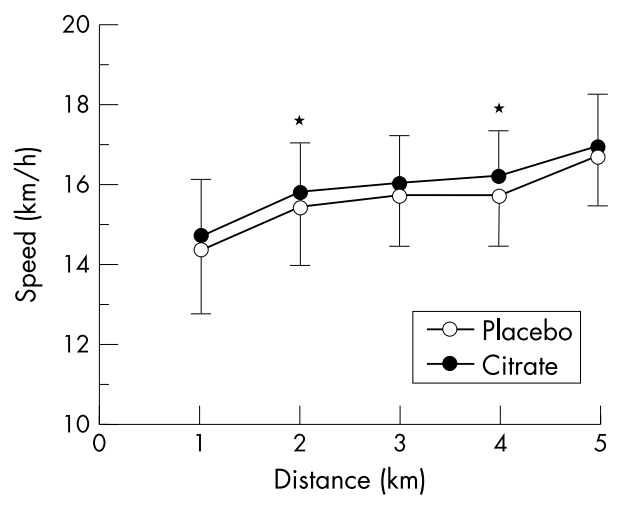

Figure 1 Mean (SD) running speed of the 17 subjects at each kilometre of the $5 \mathrm{~km}$ treadmill run. * Significantly different $(p \leqslant 0.05)$ from the placebo trial. run in well trained college runners. The subjects covered the distance on average 30.6 seconds faster after receiving citrate than after receiving the placebo. A disadvantage of this study is that the coefficient of variation for $5 \mathrm{~km}$ treadmill runs in these subjects was not measured before the experimental trials. However, all the subjects had previous experience in treadmill running. Moreover, the treatments were administered in a counterbalanced manner-that is, nine subjects performed the CIT trial first while the other eight subjects started with the PLC trial. The effect of learning on the results should be negligible under these conditions, and the fact that 13 of the 17 athletes achieved a better result after sodium citrate ingestion probably reflects the true ergogenic effect of this substance.

The use of buffering substances as ergogenic aids during endurance exercise has previously been studied. Sodium bicarbonate and sodium citrate have been shown to have no significant effect on running time to exhaustion. ${ }^{22-24}$ The subjects in those experiments were not allowed to alter their running pace, whereas in our investigation the runners chose their exercise intensity (speed of running) according to how they felt during the $5 \mathrm{~km}$ run. This is more representative of a competitive athletic event.

Three previous studies have shown an ergogenic effect of sodium citrate ${ }^{26}$ or sodium bicarbonate ${ }^{25} 27$ during endurance exercise performed on a cycle ergometer. In two, ${ }^{26}{ }^{27}$ an intermittent intensity exercise model was used, as in our study. However, to the best of our knowledge, this investigation is the first to show improvement in endurance running performance. Thus the few data so far available suggest that the probability of achieving an improvement in endurance performance by ingestion of sodium citrate or sodium bicarbonate may be greater in cycling than running. In this respect, it is noteworthy that the changes in body mass during the two hour period after consumption of 1 litre of solution indicate significantly greater fluid retention with sodium citrate treatment compared with placebo (table 1). This could be expected because the sodium content of the sodium citrate drink was much higher than that of the placebo. Therefore, immediately before the run, the subjects in the CIT trial were heavier than those in the PLC trial (table 1). Consequently, owing to their approximately $1 \%$ greater body mass, they had extra work to perform during the run. This additional work load probably reduced the positive effect of sodium citrate ingestion on running capacity and at least partly explains why the improvement in performance of our subjects was relatively small compared with that observed in other studies in which endurance capacity was measured by cycle ergometry..$^{25-27}$

The precise mechanism by which sodium citrate ingestion before the $5 \mathrm{~km}$ time trial improved performance in our well trained college runners remains obscure. Ingestion of sodium citrate has been shown to increase blood $\mathrm{pH}, \mathrm{HCO}_{3}$ concentration, and base excess. ${ }^{6}{ }^{1322} 2628$ The monocarboxylate transporter, which is thought to be responsible for lactate transport across the cell membrane, ${ }^{31}$ has been shown to be sensitive to $\mathrm{pH}$ gradient. ${ }^{32}$ Thus ingestion of sodium citrate, by increasing extracellular $\mathrm{pH}$, may create a favourable $\mathrm{pH}$ gradient for efflux of intracellular lactate and $\mathrm{H}^{+}$. In the case of an intensively working skeletal muscle, this means a delay in the fall in intramuscular $\mathrm{pH}$ to the critical level at which glycolysis is inhibited. Against this background, it is not surprising that $\operatorname{two}^{26}{ }^{27}$ of the three groups who have found a positive effect of alkalisers on endurance performance capacity have concluded that the effect is probably due to increased efflux of intracellular lactate and $\mathrm{H}^{+}$from contracting muscle cells.

Unfortunately we did not investigate the changes in blood $\mathrm{pH}, \mathrm{HCO}_{3}{ }^{-}$concentration, and base excess. However, the 


\begin{tabular}{|c|c|c|c|c|c|}
\hline \multirow[b]{2}{*}{ Treatment } & \multicolumn{2}{|c|}{ Packed cell volume (\%) } & \multicolumn{2}{|c|}{ Haemoglobin (g/100 ml) } & \multirow{2}{*}{$\begin{array}{l}\text { Change in plasma } \\
\text { volume (\%) }\end{array}$} \\
\hline & Before run & After run & Before run & After run & \\
\hline $\begin{array}{l}\text { Placebo } \\
\text { Citrate }\end{array}$ & $\begin{array}{l}44.5(2.6) \\
42.5(1.9) \dagger\end{array}$ & $\begin{array}{l}45.8(2.7)^{*} \\
43.7(2.2)^{*}+\end{array}$ & $\begin{array}{l}15.3(1.0) \\
14.7(1.2) \dagger\end{array}$ & $\begin{array}{l}15.6(0.9)^{*} \\
15.1(1.1)^{*}+\end{array}$ & $\begin{array}{l}-4.5(3.1) \\
-4.9(3.8)\end{array}$ \\
\hline \multicolumn{6}{|c|}{$\begin{array}{l}\text { Values represent mean }(S D) \text {. } \\
\text { *Significantly different }(p \leqslant 0.05) \text { from before run. } \\
\text { †Significantly different }(p \leqslant 0.05) \text { from placebo treatment. }\end{array}$} \\
\hline
\end{tabular}

dose of sodium citrate used ( $0.5 \mathrm{~g} / \mathrm{kg}$ body mass) has been reported to be the most appropriate for inducing the greatest increase in blood $\mathrm{HCO}_{3}$ concentration ${ }^{9}$ and achieving an optimal alkalotic state 100-120 minutes after ingestion. ${ }^{22}$ Our subjects started the $5 \mathrm{~km}$ run 120 minutes after ingesting the citrate or placebo. The significantly higher lactate concentration measured in the plasma of our subjects after the run in the CIT trial compared with the PLC trial (table 3 ) is in accordance with the hypothesis that lactate efflux from muscle cells is facilitated during exercise after sodium citrate ingestion. This, in turn, may have increased the contribution of anaerobic glycolysis to energy production, enabling the subjects to maintain a higher speed during certain parts of the trial and to finish it faster. In this context, the lower glucose concentration observed after the run in the subjects in the CIT trial compared with those in the PLC trial (table 3) may be explained by the increased uptake of blood sugar by the muscles because of the more intense work that they had to perform after sodium citrate ingestion.

Mitchell et $a l^{25}$ found that, in exercise performed at $80 \%$ $\dot{\mathrm{V}}_{2} \mathrm{MAX}$, intravenous infusion of both sodium bicarbonate and sodium chloride improved endurance performance compared with control conditions (no infusion), although only sodium bicarbonate prevented the development of acidosis. In this situation, the ergogenic effect may be attributed to not only the enhanced buffering capacity of the body, but also to the increased plasma volume resulting from the infusion of sodium-containing fluids, which would result in better perfusion of the exercising skeletal muscle. ${ }^{25}$

The significantly lower packed cell volume and blood haemoglobin concentration observed before the run in the CIT trial compared with the PLC trial (table 2) may reflect the increased plasma volume induced by administration of the CIT solution. It has been shown that most of the sodium absorbed from the intestinal tract remains in the extracellular fluids. ${ }^{33}$ Moreover, a sodium load comparable to that used in this study (CIT trial) has been shown to result in an approximately 1 litre increase in plasma volume, which may persist for more than three hours after ingestion of sodium-containing solution. ${ }^{34}$ Although the relative decrease in plasma volume during the $5 \mathrm{~km}$ run was similar in the two trials (table 2), the increase in plasma volume before the start of exercise in the CIT trial may also have contributed to the enhanced endurance. To some extent this notion is supported by the observation that a plasma volume expansion of $11 \%$ with no changes in erythrocyte volume was related to a $6 \%$ increase in $\dot{\mathrm{V}}_{2} \mathrm{MAX}^{35}$ The mechanism of action of increased plasma volume on endurance performance remains obscure. The explanation proposed by Mitchell et al ${ }^{25}$ (better perfusion of the exercising skeletal muscle) is speculative and requires further study. Moreover, as an increase in plasma volume probably alters sensory feedback to the brain, the possibility that central control of muscular function during exercise is also altered cannot be ignored.

Heart rate and rating of perceived exertion were similar in the two trials. These findings are in accordance with other results. 22252628

Alkalisers, especially sodium bicarbonate, ${ }^{36}$ have been reported to induce gastrointestinal distress after ingestion. The side effects of sodium citrate observed in this study included nausea and thirst in 12 subjects combined with headache in two of them. Moreover, all 17 subjects reported an urge to defecate or diarrhoea after citrate ingestion. However, they remarked that these disturbances were comparatively mild and transient, occurring within the first hour. Schabort et al ${ }^{28}$ reported that gastrointestinal discomfort and stomach cramps were experienced by five of their eight subjects during a $40 \mathrm{~km}$ cycling time trial after ingestion of $0.6 \mathrm{~g}$ of sodium citrate/ $\mathrm{kg}$ body mass, with only two subjects complaining of symptoms after ingestion of the $0.4 \mathrm{~g} / \mathrm{kg}$ body mass dose. Similarly, Potteiger et $\mathrm{al}^{26}$ mentioned that some gastrointestinal distress was associated with consumption of $0.5 \mathrm{~g}$ of sodium citrate/ $\mathrm{kg}$ body mass in three out of their eight subjects. In contrast, no gastrointestinal discomfort was reported in two other studies, ${ }^{937}$ although $0.5 \mathrm{~g} / \mathrm{kg}$ body mass doses of sodium citrate were consumed by the subjects participating. Thus it is evident that the ingestion of sodium citrate at a dose of $0.4-0.6 \mathrm{~g} / \mathrm{kg}$ body mass has the potential to cause gastrointestinal distress. Because the response seems to vary between individuals, the efficacy of sodium citrate should be individually tested by the athletes before using it as an ergogenic aid in competitions. Moreover, before sodium citrate ingestion can be recommended for improvement of endurance performance in an actual competitive situation, appropriate field studies should be undertaken to prove the efficacy of this manipulation.

In conclusion, the results of the study indicate that the ingestion of $0.5 \mathrm{~g}$ of sodium citrate $/ \mathrm{kg}$ body mass improves

Table 3 Changes in the concentrations of lactate and glucose in plasma

\begin{tabular}{|c|c|c|c|c|}
\hline Metabolite & Treatment & Before run & After run & Change \\
\hline \multirow[t]{2}{*}{ Lactate (mmol/l) } & Placebo & $2.0(0.9)$ & $9.8(2.8)^{*}$ & $7.8(2.4)$ \\
\hline & Citrate & $2.2(1.1)$ & $11.9(3.0)^{*} \dagger$ & $9.7(2.3) \dagger$ \\
\hline \multirow[t]{2}{*}{ Glucose (mmol/l) } & Placebo & $5.0(0.6)$ & $8.8(1.7)^{*}$ & $3.8(1.8)$ \\
\hline & Citrate & $4.9(0.7)$ & $8.3(1.9)^{*} \dagger$ & 3.4 (1.9) \\
\hline
\end{tabular}




\section{Take home message}

- Ingestion of sodium citrate shortly before endurance running may improve performance

- Ingestion of sodium citrate at a dose of $0.4-0.6 \mathrm{~g} / \mathrm{kg}$ body mass has the potential to cause gastrointestinal distress

- The efficacy of sodium citrate should be individually tested before its use as an ergogenic aid in competitions

$5 \mathrm{~km}$ running time trial performance in well trained college runners. The precise mechanism of action remains to be elucidated.

\section{ACKNOWLEDGEMENTS}

This study was partly supported by the Estonian Science Foundation, grant No 3930. We thank Ms Mare Vene for excellent technical assistance.

\section{Authors' affiliations}

V Ö̈pik, I Saaremets, L Medijainen, K Karelson, T Janson, S Timpmann, Institute of Exercise Biology, University of Tartu, Tartu, Estonia

\section{REFERENCES}

1 Green HJ. Metabolic determinants of activity induced muscular fatigue. In: Hargreaves M, ed. Exercise metabolism. Champaign, IL: Human Kinetics Publishers, 1995:211-56.

2 Sutton JR, Jones NL, Toews CJ. Effect of $\mathrm{pH}$ on muscle glycolysis during exercise. Clin Sci 1981;61:331-8.

3 Fuchs F, Reddy Y, Briggs FN. The interaction of cations with the binding site of troponin. Biochim Biophys Acta 1969;221:407-9.

4 Chase PB, Kushmerick M. Effect of $\mathrm{pH}$ on the contraction of rabbit fast and slow skeletal muscle fibres. Biophys J 1988;53:935-46.

5 McNaughton L, Backx K, Palmer G, et al. Effects of chronic bicarbonate ingestion on the performance of high-intensity work. Eur J Appl Physiol 1999:80:333-6.

6 Linossier MT, Dormois D, Bregere P, et al. Effect of sodium citrate on performance and metabolism of human skeletal muscle during supramaximal cycling exercise. Eur J Appl Physiol 1997;76:48-54.

7 Bird SR, Wiles J, Robbins J. The effect of sodium bicarbonate ingestion on 1500-m racing time. J Sports Sci 1995; 13:399-403.

8 McNaughton LR, Cedaro R. The effect of sodium bicarbonate on rowing ergometer performance in elite rowers. Aust J Sci Med Sport 1991;23:66-9.

9 McNaughton L. Sodium citrate and anaerobic performance: implications of dosage. Eur J Appl Physiol 1990;61:392-7.

10 Goldfinch J, McNaughton L, Davies P. Induced metabolic alkalosis and its effects on $400 \mathrm{~m}$ racing time. Eur J Appl Physiol 1988;57:45-8.

11 Wilkes D, Gledhill N, Smyth R. Effect of acute induced metabolic alkalosis on $800 \mathrm{~m}$ racing time. Med Sci Sports Exerc 1983:15:277-80.

12 Ball D, Maughan RJ. The effect of sodium citrate ingestion on the metabolic response to intense exercise following diet manipulation in man. Exp Physiol 1997;82:1041-56.
13 Tiryaki GR, Atterbom HA. The effects of sodium bicarbonate and sodium citrate on $600 \mathrm{~m}$ running time of trained females. J Sports Med Phys Fitness 1995;35:194-8.

14 Ibanez J, Pullinen T, Gorostiaga E, et al. Blood lactate and ammonia in shortterm anaerobic work following induced alkalosis. J Sports Med Phys Fitness 1995;35: 187-93.

15 Lambert CP, Greenhaff PL, Ball D, et al. Influence of sodium bicarbonate ingestion on plasma ammonia accumulation during incremental exercise in man. Eur J Appl Physiol 1992;63:338-44.

16 Katz A, Costill DL, King DS, et al. Maximal exercise tolerance after induced alkalosis. Int J Sports Med 1984;5:107-10.

17 Marx JO, Gordon SE, Vos NH, et al. Effect of alkalosis on plasma epinephrine responses to high intensity cycle exercise in humans. Eur J Appl Physiol 2002;87:72-7.

18 Osnes J-B, Hermansen L. Acid-base balance after maximal exercise of short duration. J Appl Physiol 1972;32:59-63.

19 Cryer PE. Regulation of glucose metabolism in man. J Int Med 1991;229/suppl 2):31-9.

20 Bouissou P, Defer G, Guezennec CY, et al. Metabolic and blood catecholamine responses to exercise during alkalosis. Med Sci Sports Exerc 1988;20:228-32.

21 Meeusen R. Overtraining and the central nervous system. The missing link? In: Lehmann M, Foster C, Gastmann U, et al, eds. Overload, performance incompetence, and regeneration in sport. Dordrecht: Kluwer Academic/ Plenum Publishers, 1999:187-202.

22 Potteiger JA, Webster MJ, Nickel GL, et al. The effects of buffer ingestion on metabolic factors related to distance running performance. Eur J Appl Physiol 1996:72:365-71.

23 George KP, MacLaren DPM. The effect of induced alkalosis and acidosis on endurance running at an intensity corresponding to $4 \mathrm{mM}$ blood lactate. Ergonomics 1988;31:1639-45.

24 Hooker S, Morgan C, Wells C. Effect of sodium bicarbonate ingestion on time to exhaustion and blood lactate of $10 \mathrm{~km}$ runners. Med Sci Sports Exerc 1987; 19:S67.

25 Mitchell TH, Abraham G, Wing S, et al. Intravenous bicarbonate and sodium chloride both prolong endurance during intense cycle ergometer exercise. Am J Med Sci 1990;300:88-97.

26 Potteiger JA, Nickel GL, Webster MJ, et al. Sodium citrate ingestion enhances $30 \mathrm{~km}$ cycling performance. Int J Sports Med 1996;17:7-11.

27 McNaughton L, Dalton B, Palmer G. Sodium bicarbonate can be used as an ergogenic aid in high-intensity, competitive cycle ergometry of $1 \mathrm{~h}$ duration. Eur J Appl Physiol 1999;80:64-9.

28 Schabort EJ, Wilson G, Noakes TD. Dose-related elevation in venous $\mathrm{pH}$ with citrate ingestion do not alter 40-km cycling time-trial performance. Eur J Appl Physiol 2000;83:320-7

29 Conconi F, Ferrari M, Ziglio PG, et al. Determination of the anaerobic threshold by a noninvasive field test in runners. J Appl Physiol 1982;52:869-73.

30 Dill DB, Costill DL. Calculation of percentage changes in volumes of blood, plasma, and red cells in dehydration. J Appl Physiol 1974;37:247-8.

31 Roth DA. The sarcolemmal lactate transporter: transmembrane determinants of lactate flux. Med Sci Sports Exerc 1991;23:925-34.

32 Roth DA, Brooks GA. Lactate and pyruvate transport is dominated by a $\mathrm{pH}$ gradient-sensitive carrier in rat skeletal muscle sarcolemmal vesicles. Arch Biochem Biophys 1990;279:386-94.

33 Lindinger MI, Lands LC, Pedersen PK, et al. Role of skeletal muscle in plasma ion and acid-base regulation after $\mathrm{NaHCO}_{3}$ and $\mathrm{KHCO}_{3}$ loading in humans. Am J Physiol 1999;276:R32-R43.

34 Lindinger MI, Franklin TW, Lands $\mathrm{LC}$, et al. $\mathrm{NaHCO}_{3}$ and $\mathrm{KHCO}_{3}$ ingestion rapidly increases renal electrolyte excretion in humans. J Appl Physiol 2000;88:540-50.

35 Sawka MN, Convertino VA, Eichner ER, et al. Blood volume: importance and adaptations to exercise training, environmental stresses, and trauma/sickness. Med Sci Sports Exerc 2000;32:332-48.

36 Linderman JK, Gosselink KL. The effects of sodium bicarbonate ingestion on exercise performance. Sports Med 1994;18:75-80.

37 McNaughton L, Cedaro R. Sodium citrate ingestion and its effects on maximal anaerobic exercise of different duration. Eur J Appl Physiol 1992;64:36-41. 